\title{
A novel method to produce carbon nanotubes using EDM process
}

\author{
Y.Y. Tsai ${ }^{\text {a,*}}$, J.S. Su ${ }^{\text {a }}$, C.Y. Su ${ }^{\text {b }}$ \\ ${ }^{a}$ Department of Mechanical Engineering, National Taiwan University, No. 1, Section 4, Roosevelt Road, Taipei, Taiwan \\ ${ }^{\mathrm{b}}$ Department of Mechanical Engineering, National Taipei University of Technology, Taiwan
}

\section{A R T I C L E I N F O}

\section{Article history:}

Received 1 March 2008

Received in revised form

28 June 2008

Accepted 7 July 2008

Available online 22 July 2008

Keywords:

Carbon nanotubes (CNTs)

Single-pulse discharge

Pulse duration

Peak current

\begin{abstract}
A B S T R A C T
Carbon nanotubes (CNTs) have been used in various fields of research due to their unique properties. There are various methods such as arc discharge, laser ablation, chemical vapor deposition (CVD), template-directed synthesis and the use of the growth of CNTs in the presence of catalyst particles. Special ambient gas is required for the fabrication of CNTs, in order to prevent the oxidation of carbon at high temperature. In this study, we developed a simple, fast and low cost method in which CNTs can be fabrication by single-pulse discharge with low energy in air. The single-pulse discharge system was designed to adjust the peak current and pulse duration. A graphite rod electrode generated an electric arc between electrode and the substrate at a distance of $1 \mu \mathrm{m}$. A promising result was obtained by using single-pulse discharge with a pulse duration of $1000 \mu$ s and peak current of $2.5 \mathrm{~A}$; that is, many CNTs grew on the substrate under these conditions. This method can overcome the limitations of the special ambient gas and enable the fabrication of CNTs at a selected location on the substrate.
\end{abstract}

(c) 2008 Elsevier Ltd. All rights reserved.

\section{Introduction}

Since the development of carbon nanotubes (CNTs) in 1991 [1], there has been considerable interest in CNTs with unique properties. Due to the unique mechanical, electrical and chemical properties of nanometer-scale tubular forms of CNTs [2,3], they have been considered as important components of numerous microscale and/or nanoscale sensors [4-6] and also used in many nanoscale applications. Various methods have been used for growing CNTs in the presence of catalyst particles. The principal methods for producing CNTs are arc discharge method [7-10], chemical vapor deposition (CVD) method [11,12] and laser ablation [13]. The CVD method is extremely suitable for batch production of CNTs; however, this method usually requires the predeposition of a catalyst layer on a suitable substrate and preheats the substrate to a high temperature of $500-1300{ }^{\circ} \mathrm{C}$. For producing CNTs at a selected location, CVD requires some complicated procedures such as etching, deposition and masking. In the arc discharge process, CNTs are easily produced at a location that is in the front of the electrode containing carbon. This method can deposit CNTs at the selected location without any mask. However, the arc discharge method usually requires a vacuum environment and special ambient gas (helium or hydrogen) to produce multiwalled CNTs. The laser ablation method is similar to

\footnotetext{
* Corresponding author. Tel.: +886233662 714; fax: +886223631755.

E-mail address: yytsai@ntu.edu.tw (Y.Y. Tsai).
}

the arc discharge method, but it uses an expensive high-energy laser instead of the arc discharge to heat the graphite catalyst. The vaporized graphite is suddenly cooled to grow CNTs. Some ambient gas and high temperature are also required for the growth of CNTs; however, the production rate of this method is low.

A simple process for fabricating CNTs at a selected location will be beneficial to the development of nanoelectronic devices and biological probes. As for CVD method, a usual and common method to produce CNTs, its environment has serious requirement and its leadtime is longer. The arc discharge method has attracted attention due to its easy operation and ability to produce CNTs at a selected location. Sugai et al. [7] have grown singlewalled CNTs by utilizing pulsed arc discharge (22 A at a duration of more than $1 \mathrm{~ms}$ ) in helium or hydrogen gas at an atmospheric pressure of $500 \mathrm{~T}$ and a temperature of $1000^{\circ} \mathrm{C}$. Takikawa et al. [14] have used a continuous arc torch to produce CNTs. Recently, Parkansky et al. [15] have utilized a few short-pulsed arc discharges (7-100 A, $0.2-20 \mu \mathrm{s}$ ) in ambient air in order to produce multiwalled nanotubes at room temperature.

In order to overcome the limitation of conventional technology, we attempted to develop a simple, fast and low cost method to produce CNTs. We used a short single pulse to generate arc discharge in air at room temperature. The graphite electrode can be moved to selected locations on the substrate. After numerous pulses of arc discharge, CNTs will be produced on substrate under simple environment without vacuum and special ambient gas. 


\section{Experimental}

\subsection{Substrate and electrode}

The structure, quality and quantity of CNTs are dependent on its production method and catalyst particles. Catalyst particle are the decisive factors for the formation of CNTs, including the type, grain size and concentration of a catalyst. Elements such as $\mathrm{Fe}, \mathrm{Co}$, $\mathrm{Ni}$ or $\mathrm{Cu}$ are commonly used as catalysts. In addition, La, Y element as catalyst also shows a good result. In this study, we used Fe, which is one of the most common types of catalyst, and precoated it on a substrate by plasma sputtering equipment; this sputtering apparatus is shown in Fig. 1. The graphite substrate was cut into an appropriate size and its surface was polished in order to improve the surface roughness. The electrode material was also selected as graphite to obtain a sufficiently large number of carbon atoms. The physical properties of graphite are listed in Table 1.

\subsection{Experimental equipment and process}

The general arc discharge method requires a constant peak current of above $50 \mathrm{~A}$ for several minutes; hence, it requires special gas to prevent the oxidation or burning of carbon. In our mind, if discharge energy was reduced but the pulse energy intensity was still enough, it is possible to avoid high-temperature oxidation. Therefore, we attempted to produce CNTs under an atmosphere utilizing single-pulse discharge with a low peak current and short-pulse duration. The peak current (Ip) and pulse duration (Td) are regarded as the main parameters in this study. During single discharge, a semispherical-like point with a diameter range from 70 to $90 \mu \mathrm{m}$ and depth from 25 to $30 \mu \mathrm{s}$ is formed on the substrate and it just offers a collection of carbon molecule as a result in CNT growth. For this reason, discharge current and pulse duration are the most important parameters with concern of low or high energy. After numerous experiments and adjustment of parameter range, the influence of discharge energy on CNT growth is found. Table 2 shows the experimental parameters.

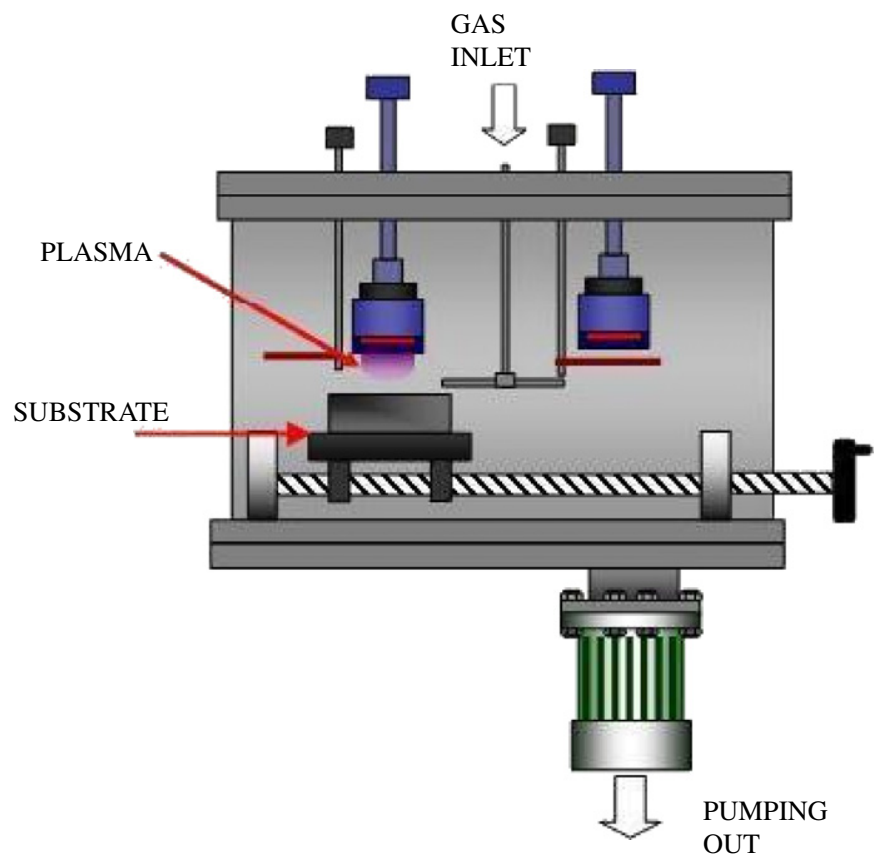

Fig. 1. Schematic representation of plasma sputtering apparatus.
Table 1

Physical properties of graphite

\begin{tabular}{lc}
\hline Apparent density $\left(\mathrm{g} / \mathrm{cm}^{3}\right)$ & 1.8 \\
Compressive strength $\left(\mathrm{kg} / \mathrm{cm}^{2}\right)$ & 950 \\
Thermal conductivity $\left(\mathrm{kcal} / \mathrm{m} \mathrm{h}^{\circ} \mathrm{C}\right)$ & 100 \\
Electric resistance $(\mu \Omega \mathrm{cm})$ & 1200 \\
Graphite purity $(\%)$ & 99.99 \\
\hline
\end{tabular}

Table 2

Experimental parameters

\begin{tabular}{ll}
\hline Electrode material & Graphite \\
Substrate & Graphite with Fe coated \\
Peak current (Ip) & $2,2.5 \mathrm{~A}$ \\
Pulse duration (Td) & $800,1000,1300 \mu \mathrm{s}$ \\
Times of pulse discharge & 4 \\
Discharge gap & $1 \mu \mathrm{m}$ \\
\hline
\end{tabular}

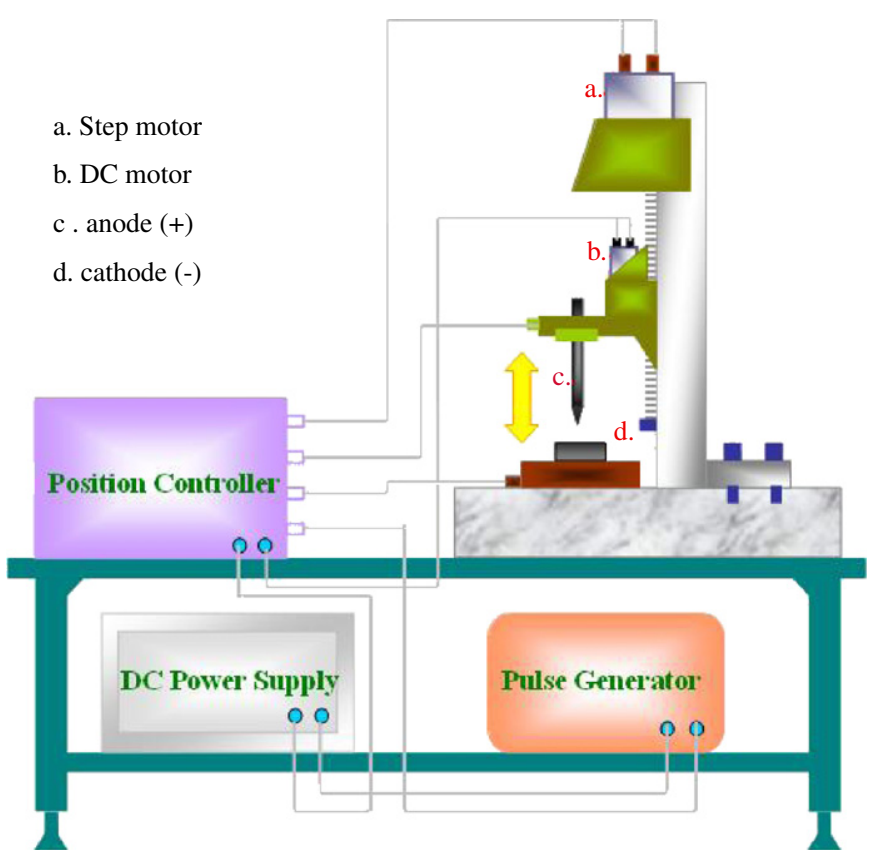

Fig. 2. Schematic representation of prototype microelectric discharge apparatus.

All experiments were carried out using a microelectric discharge machine with single-pulse discharge circuit, which was completely set up by us. A rod with a diameter of $5 \mathrm{~mm}$ and a conical angle of $60^{\circ}$ was used as an electrode. As shown in Fig. 2, a graphite electrode and a substrate were connected to the anode and cathode, respectively. Using stepping motor in the direction of $Z$-axis was to control the appropriate gap of $1 \mu \mathrm{m}$ between the electrode and the substrate. Single-pulse discharge was generated by a transistor circuit designed with adjustable peak current and pulse duration. Fig. 3 shows the schematic representation of the discharge circuit. The resulting CNTs were examined by scanning electron microscopy (SEM) and transmission electron microscopy (TEM) in order to observe the quality and characteristics of the CNTs.

\section{Experimental results and discussions}

\subsection{Conditions of single-pulse discharge for CNTs production}

The peak current and pulse duration have a significant effect on the production of CNTs. Figs. 4 and 5 show SEM (FEG-SEM, LEO 


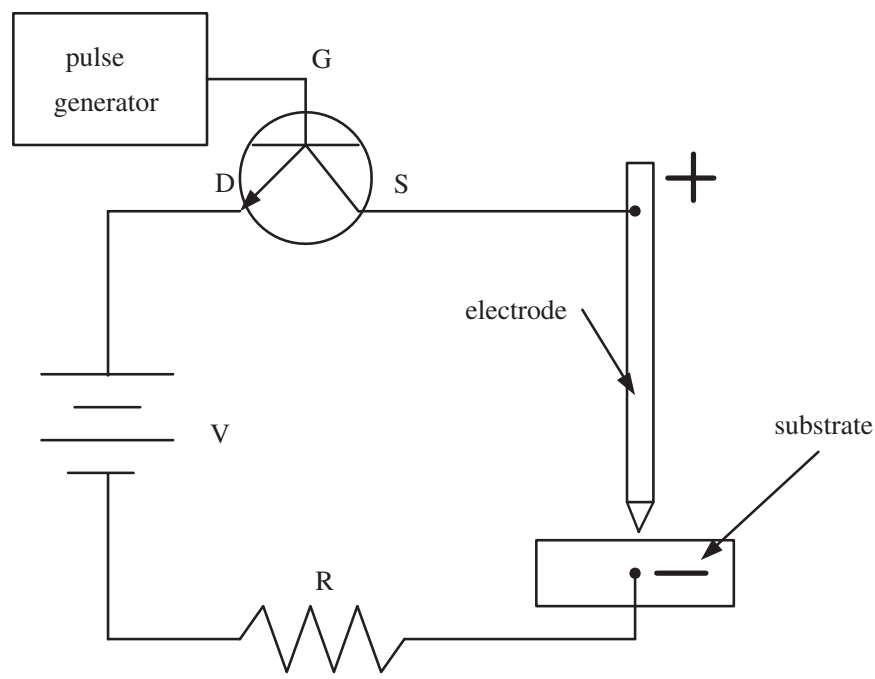

Fig. 3. Schematic representation of a single pulse discharge circuit.

1530, Germany) images of processing locations for different pulse durations ranging from 800 to $1300 \mu$ s at peak currents of 2 and $2.5 \mathrm{~A}$, respectively. From the figures, it is observed that the differences in the parameters lead to the production of CNTs with various structures and quantity. When single-pulse discharge is used with a low energy, peak current of $2 \mathrm{~A}$ and pulse duration $800 \mu \mathrm{s}$, the growth of CNTs was rarely observed. At a peak current of $2 \mathrm{~A}$ and pulse duration of $1000 \mu \mathrm{s}$, the formation of CNTs was observed at the pinpoint; further for pulse duration of $1300 \mu \mathrm{s}$, some amorphous carbons and impurities are found, as shown in Fig. 4(b). The number of CNTs and their length increases with the pulse duration. A comparison of Figs. 4 and 5 indicates that different types of CNT are formed. CNTs presented pinpoint form when peak current was $2 \mathrm{~A}$ for pulse duration of $1000 \mu$ s but grew long and direct when peak current was $2.5 \mathrm{~A}$. However, in the case of a peak current of $2.5 \mathrm{~A}$ and pulse duration of $1300 \mu \mathrm{s}$, no CNTs but carbon clusters are observed, as shown in Fig. 5(c). If the peak current is very large, CNTs cannot be produced because a large amount of heat and semispherical-like discharge point are generated. The measurement of the metal contaminants on the CNTs was done by EDX. It has shown no other element but carbon be observed because the peak current concentrates on very small discharging point $(\sim 100 \mu \mathrm{m})$ and have catalyst evaporated.

\subsection{Structure of CNTs and field emission test}

The CNTs fabricated by this method are multiwalled CNTs. By using TEM (JEOL, JEM-2010) we can investigate the structure of CNTs. Fig. 6 illustrates the TEM image of CNTs at Ip $=2.5 \mathrm{~A}$ and $\mathrm{Td}=1000 \mu \mathrm{s}$. From the TEM measurements, the inner and outer diameters of the CNTs are found to be approximately 17 and $5 \mathrm{~nm}$, respectively. Statistically, the average length of CNTs is $180 \mathrm{~nm}$. While for CVD method, the length of CNTs can achieve $850 \mu \mathrm{m}$ [16]. Thus, the length of CNTs in this research is not so long as that of CVD method. The reason is considered as growth time of CNTs is not long enough for the single-pulse pulse duration. Moreover, the CNTs are coated with an amorphous carbon layer having a thickness of 3-5 $\mathrm{nm}$ in the presence of a catalyst deposited on the surface of the substrate. To prevent the oxidation of the CNTs, both appropriated energy and catalyst particles are essential under open atmosphere.

By the single-pulse discharge technique, we can prepare CNTs on predetermined positions under atmospheric environment. The percentage and quality of CNTs differed for different processing

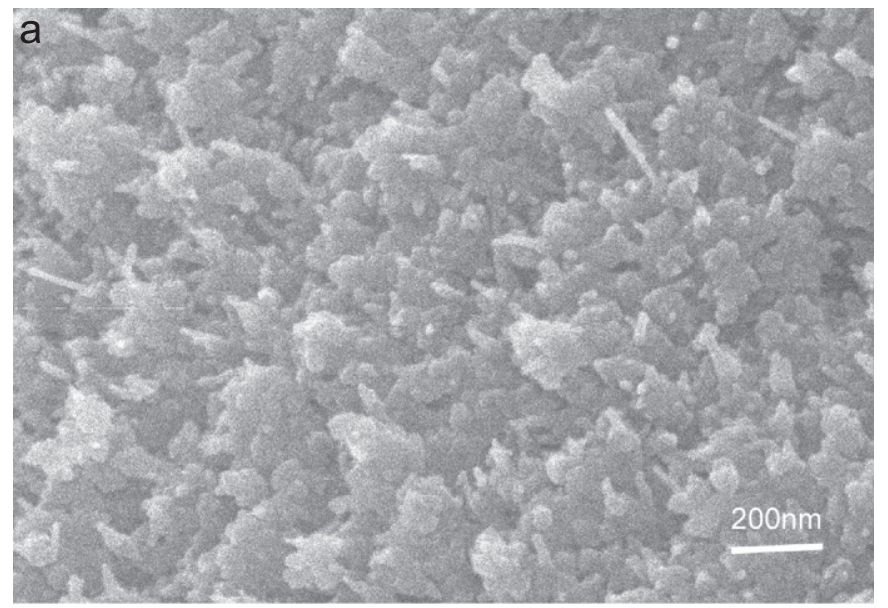

$\mathrm{Td}=800 \mu \mathrm{s}$

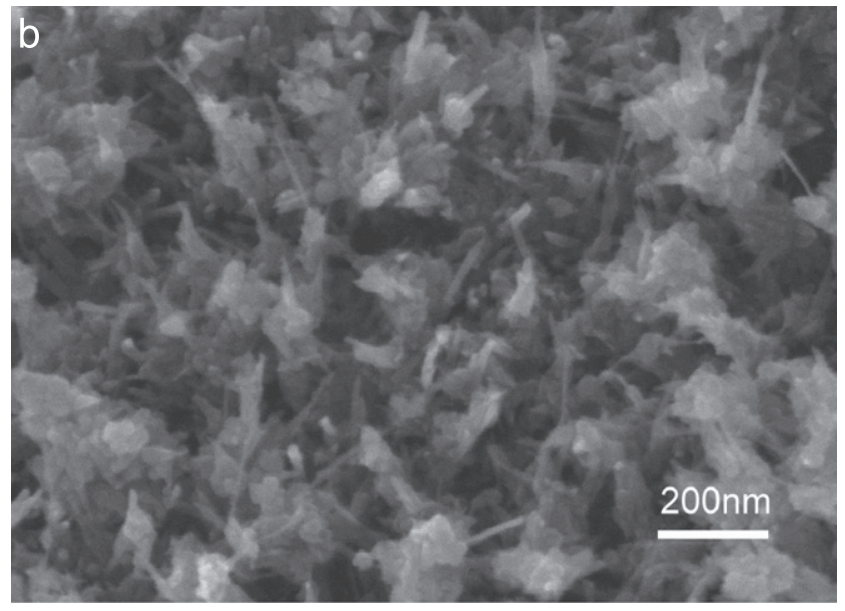

$\mathrm{Td}=1000 \mu \mathrm{s}$

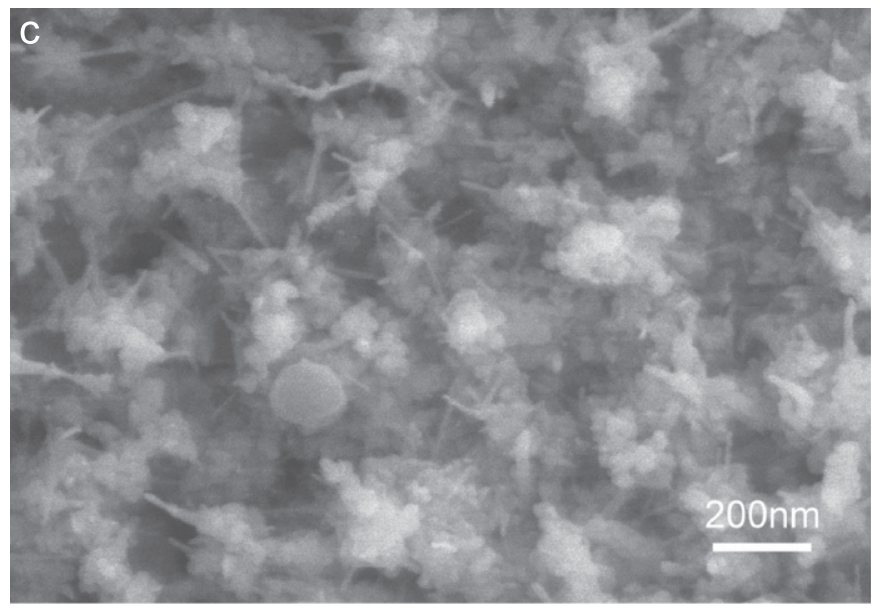

$\mathrm{Td}=1300 \mu \mathrm{s}$

Fig. 4. SEM images of single pulse discharge Ip $=2 \mathrm{~A}$.

parameters. Field emission test was performed by Keithley 237 under vacuum of $5 \times 10^{-7}$ torr. Fig. 7 plots the relationship between the emission current density $(J)$ and applied filed $(E)$. Here, we define the turn-on field as the electric field required to produce a current density of $10 \mu \mathrm{A} / \mathrm{cm}^{2}$. The result without any post-processes reveals that CNTs have a turn-on field of 5 and $4 \mathrm{~V} / \mu \mathrm{m}$ for the samples prepared by peak current of 2.0 and $2.5 \mathrm{~A}$ respectively, which are higher than that of CNTs prepared by 


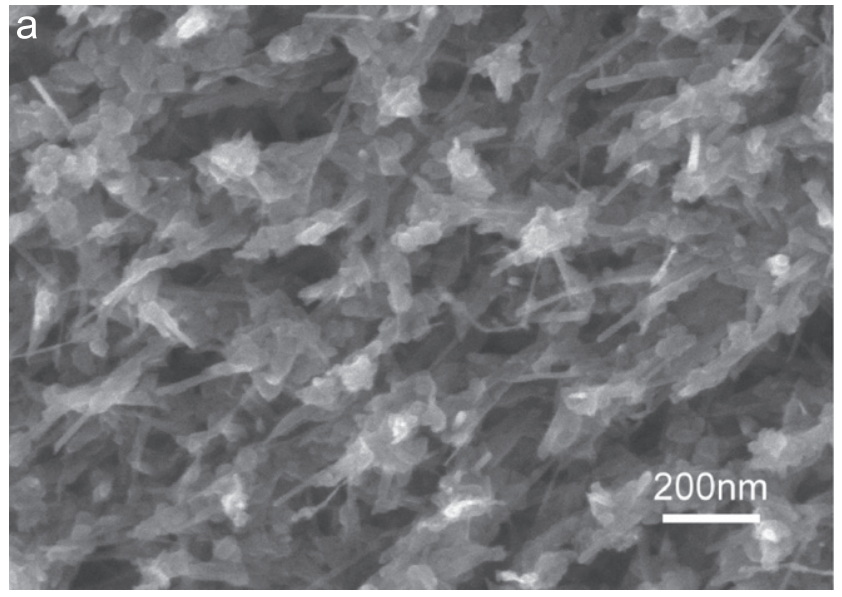

$\mathrm{Td}=800 \mu \mathrm{s}$

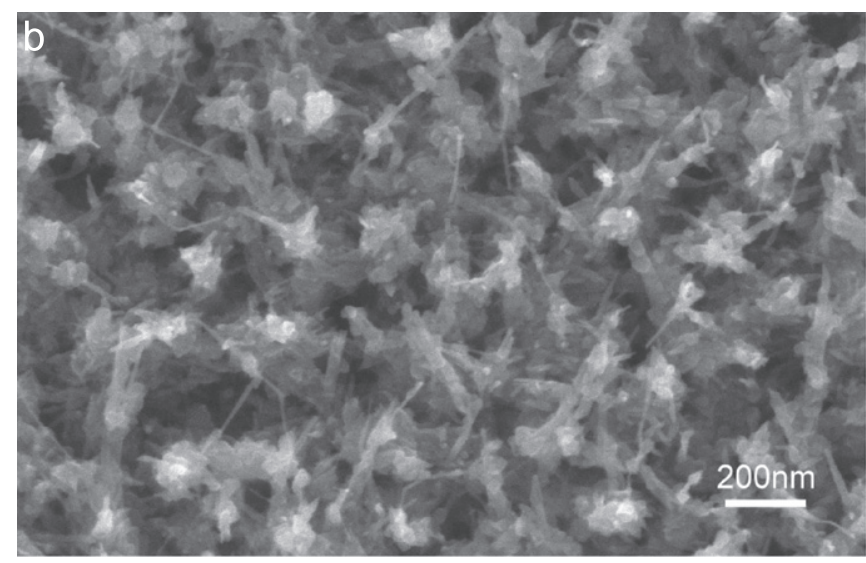

$\mathrm{Td}=1000 \mu \mathrm{s}$

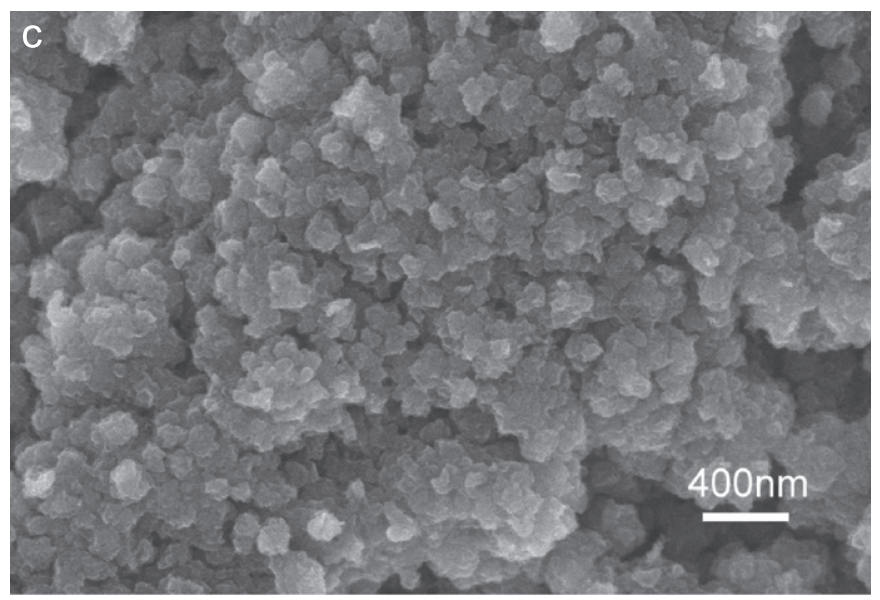

$\mathrm{Td}=1300 \mu \mathrm{s}$

Fig. 5. SEM images of single pulse discharge $\mathrm{Ip}=2.5 \mathrm{~A}$

screen-printed (the turn-on field is about 1-1.5 V) [17]. The reasons for the high turn-on field of the CNTs are considered as oxidation on the tube surface and bending structure of the CNTs. In the future work, we will devote the research on the purification and controlling growth of the CNTs.

\section{Conclusion}

In this study, a new method utilizing single-pulse discharge has been developed to fabricate CNTs in air at a selected location.

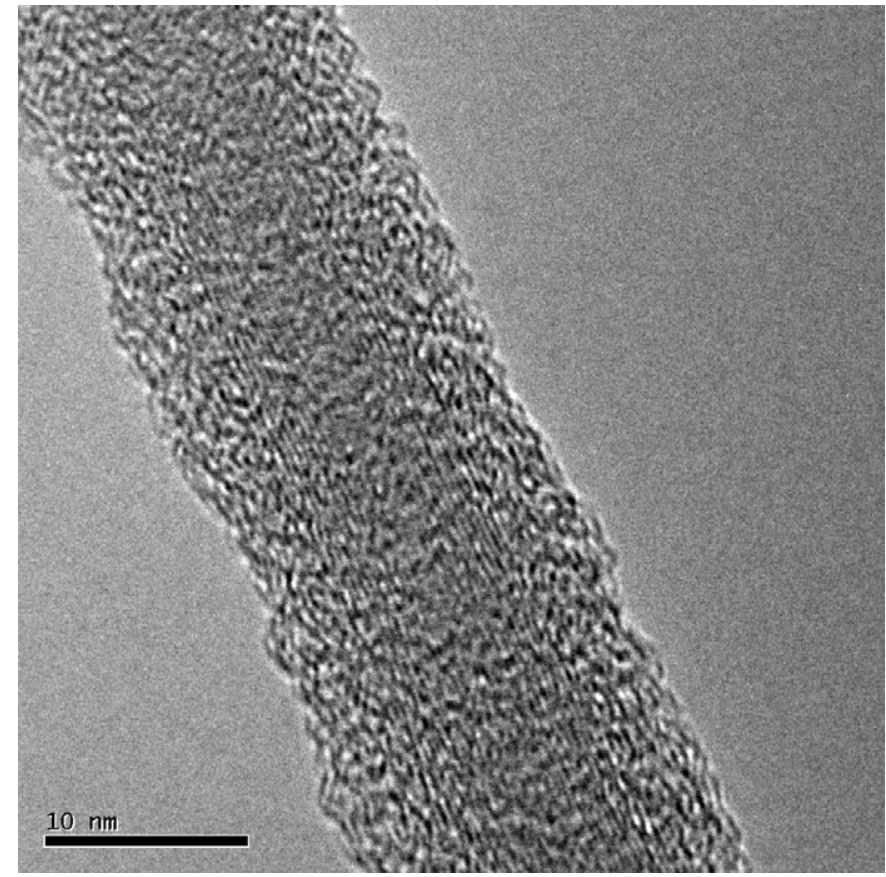

Fig. 6. TEM image of CNT at $\mathrm{Ip}=2.5 \mathrm{~A}$ and $\mathrm{Td}=1000 \mu \mathrm{s}$.

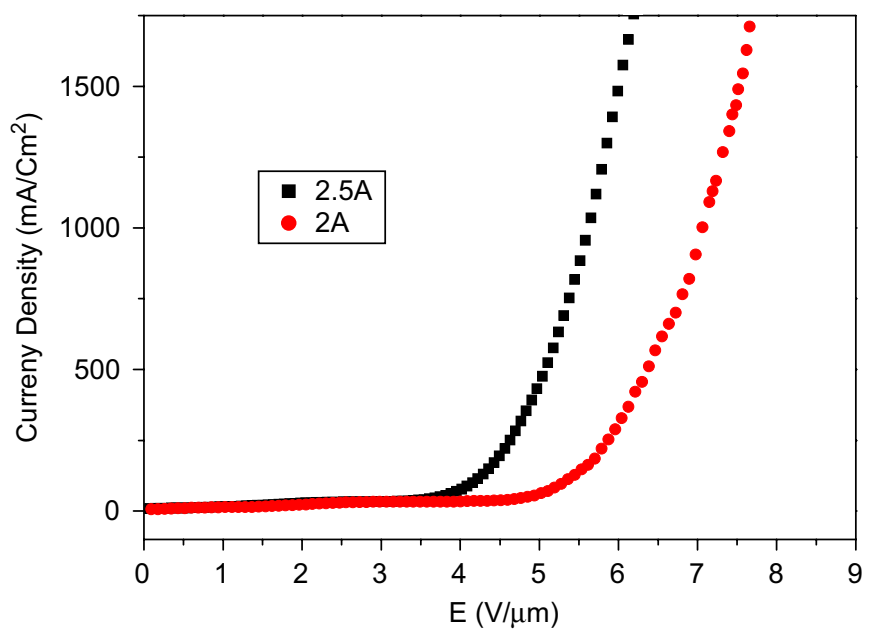

Fig. 7. Field emission $I-V$ curves for samples prepared by an electric current of 2.0 or $2.5 \mathrm{~A}$ under pulse duration of $1000 \mu \mathrm{s}$.

Both the peak current and the pulse duration are the decisive factors of this method. If the peak current and pulse duration are very high or very low, CNTs cannot be formed. Too small energy of a single pulse is unable to offer carbon molecule enough to synthesize carbon nanotubes. When the peak current is $2 \mathrm{~A}, \mathrm{CNTs}$ can be synthesized in the form of pinpoint. The produced CNTs by 2.5-A peak current grow long and direct. Further, a large peak current and pulse duration will lead to the oxidation and burning of CNTs at a high temperature. To prevent the oxidation of CNTs, the discharge pulse must have adequate energy in the open atmosphere. A promising result can be obtained by using singlepulse discharge with a pulse duration of $1000 \mu$ s and peak current of $2.5 \mathrm{~A}$.

This method successfully overcomes the limitations of vacuum environment and special ambient gas for producing CNTs. Thus, the growth area of CNTs will not be limited to the chamber. The 
CNTs obtained by this method are different from those obtained in a previous study and could be applied directly without any further preparation. Further, a CNT array can be realized by moving the graphite electrode at selected locations. We believe that this method can be used to produce CNT arrays economically and accurately for field emission devices (FEDs) in the future. The single-pulse discharge method also enables the use of EDM for the fabrication of CNTs.

\section{References}

[1] S. Iijima, Helical microtubules of graphitic carbon, Nature 354 (1991) 56-58.

[2] M. Bockrath, D.H. Cobden, P.L. Mceuen, N.G. Chopra, A. Zettl, A. Thess, R.E. Smalley, Single-electron transport in ropes of carbon nanotubes, Science 275 (1997) 1922-1925.

[3] C.F. Cornwell, L.T. Wille, Elastic properties of single-walled carbon nanotubes in compression, Solid State Communications 101 (1997) 555-558.

[4] R. Martel, T. Schmidt, H.R. Shea, T. Hertel, P. Avouris, Single- and multi-wall carbon nanotube field effect transistors, Applied Physics Letters 73 (1998) 2447-2449.

[5] J. Kong, N.R. Franklin, C. Zhou, M.G. Chapline, S. Peng, K. Cho, H. Dai, Nanotube molecular wires as chemical sensors, Science 287 (2000) 622-625.

[6] A. Bachtold, P. Hadley, T. Nakanishi, C. Dekker, Logic circuits with carbon nanotube transistors, Science 294 (2001) 1317-1320.

[7] T. Sugai, H. Omote, S. Bandow, N. Tanaka, H. Shinohara, Production of fullerenes and single-wall carbon nanotubes by high-temperature pulsed arc discharge, Journal of Chemical Physics 112 (2000) 6000-6005.
[8] J. Qiu, Y.F. Li, Y.P. Wang, T.H. Wang, Z.B. Zhao, Y. Zhou, F. Li, H.M. Cheng, Highpurity single-wall carbon nanotubes synthesized from coal by arc discharge, Carbon 41 (2003) 2170-2173.

[9] Y.N. Liu, X.L. Song, T.K. Zhao, J.W. Zhu, M. Hirscher, F. Philipp, Amorphous carbon nanotubes produced by a temperature controlled DC arc discharge, Carbon 42 (2004) 1852-1855.

[10] T.K. Zhao, Y.N. Liu, J.W. Zhu, Temperature and catalyst effects on the production of amorphous carbon nanotubes by a modified arc discharge, Carbon 43 (2005) 2907-2912.

[11] V.I. Merkulov, D.H. Lowndes, Y.Y. Wei, G. Eres, Patterned growth of individual and multiple vertically aligned carbon nanofibers, Applied Physics Letters 76 (2000) 3555-3557.

[12] N.Q. Zhao, C.N. He, J.J. Li, Z.Y. Jiang, Y.D. Li, Study on purification and tipopening of CNTs fabricated by CVD, Materials Research Bulletin 41 (2006) 2204-2209.

[13] M. Yudasaka, R. Yamada, N. Sensui, T. Wilkins, T. Ichihashi, S. Iijima, Mechanism of the effect of NiCo, $\mathrm{Ni}$ and Co catalysts on the yield of singlewall carbon nanotubes formed by pulsed Nd:YAG laser ablation, Journal of Physical Chemistry B 103 (1999) 6224-6229.

[14] H. Takikawa, M. Ikeda, K. Hirahara, Y. Hibi, Y. Tao, P.A. Ruiz Jr., T. Sakakibara, S. Itoh, S. Iijima, Fabrication of single-walled carbon nanotubes and nanohorns by means of a torch arc in open air, Physica B 323 (2002) 277-279.

[15] N. Parkansky, R.L. Boxman, B. Alterkop, I. Zontag, Y. Lereah, Z. Barkay, Singlepulse arc production of carbon nanotubes in ambient air, Journal of Physics DApplied Physics 37 (2004) 2715-2719.

[16] D.H. Kuo, M.Y. Su, W.R. Chen, Fast rate growth of organized carbon nanotubes by CVD using iron pentacarbonyl as gas-phase catalyst, Chemical Vapor Deposition 12 (2006) 395-402.

[17] K. Yoshihara, S. Fujii, H. Kawai, K. Ishida, S.I. Honda, M. Katayama, Fabrication of screen-printed field electron emitter using length-controlled and purification-free carbon nanotubes, Applied physics letters 91 (2007) 113109. 